\title{
The Quality Awards - a Toolkit for Organizational Excellence
}

\author{
Chief Assist Prof. PhD Radka Ivanova \\ University of Economics - Varna, Varna, Bulgaria \\ r.ivanova@ue-varna.bg
}

\begin{abstract}
The quality philosophy and principles for improving organizations are at the base of the quality awards and have incentives for development and improvement. The specifics of the quality awards make them a toolkit that allows self-assessment of what has been achieved and the shortcomings, identifying opportunities for success, as well as setting specific goals and objectives for fulfillment. The awards are directly related to the implementation of total quality management, which can be seen as a prerequisite for organizational excellence. The purpose of the paper is to present the potential of quality awards, and in particular the European Excellence Award, as a means of selfimprovement for organizations.
\end{abstract}

Keywords: quality, management, organizational excellence

JEL Code: O2, M1; doi:10.36997/IJUSV-ESS/2019.8.1.10

\section{Въведение}

Условията, в които днес организациите трябва да развиват дейността си, налагат търсенето на възможности за непрекъснато формиране на нови конкурентни предимства и повишаване на имиджа им сред потребителите, конкурентите, доставчиците, обществото като цяло. В основата на това стоят качествените характеристики на процесите, технологиите, продуктите, услугите и тяхното подобряване в съответствие с изискванията на заинтересованите страни. На практика ръководствата на организациите са изправени пред необходимостта от подобряване на начина на управление и протичане на процесите, ангажиране на персонала за усъвършенстване като цяло, независимо от ограничеността на ресурсите. Постигането на конкурентни предимства става чрез непрекъснатия стремеж към организационно съвършенство, като се намаляват разходите, подобряват се характеристиките на процесите, както и на резултатите, които се предлагат на обществото. Интегрирането на усилията на всеки, работещ в една организация, за нейното усъвършенстване, лежи в основата на концепцията за тотално управление на качеството. Степента на постигането му може да бъде измерена чрез критериите, изграждащи наградите за качеството, като позволяват всяка организация да оценява сама нивото, което вече е постигнала и да открива слабите си страни, за чието отстраняване следва да предвиди конкретни действия. В основата на тоталното управление е заложена идеята за това организациите да осигуряват на своите потребители такива стоки и услуги, които да удовлетворяват техните потребности във възможно най-висока степен. Това предполага цялостна промяна в начина на осъществяване на дейностите и процесите и ангажиране на всички, работещи в съответната компания. Възприемането на непрекъснатото подобряване на качеството като част от организационната култура и трансформирането му в начин на мислене, представлява предпоставка за успешното въвеждане на концепцията за тотално управление на качеството и стремеж към постоянно усъвършенстване на процесите и хората в организациите.

\section{1. Съвършенство на организациите}

Непрекъснатото усъвършенстване може да се разглежда като ключов момент в дейността на всяка организация. В тази връзка съществува тезата, че по своята същност организационното съвършенство представлява системен подход към управлението, основаващ се на подходяща съвкупност от концепции и инструменти за адаптиране към непрекъснато променящата се среда (Y. Alkalai, 2008). Постигането му предполага 
формиране и спазване на политика, балансираща интересите на различните заинтересовани страни, което може да се разглежда като предпоставка за успех в дългосрочен план. Основен акцент представлява начинът на функциониране на организациите, както и ползите за клиентите, служителите, акционерите. Счита се, че концепцията за организационно съвършенство изисква управление на пет основни компонента - процеси, проекти, ресурси, знания, промени, като основна цел представлява постоянното повишаване на ефективността (А. Ненова, 2013, с. 255). Тези компоненти се намират в причинно-следствена взаимовръзка, а именно: проектите са предназначени за усъвьршенстване на процесите, а в основата им лежат знанията на хората. Ефективността на промените се определя от своевременното осигуряване на ресурсите, необходими за извършване на тези процеси.

Понятието организационно съвършенство се свързва с управление и оптимизиране на процесите и дейностите в организациите, може да изисква промени в ценностите, в структурата, начините на работа, както и поставените цели, за да бъде организацията гъвкава към променящата се обкръжаваща среда. Както посочва К. Хаджиев, организационното съвършенство има динамичен характер и изисква непрекъснати усилия (К. Хаджиев, 2010). Предпоставка за това е и фактът, че не е възможно да се постигне усъвършенстване, ако различните аспекти от дейността на една организация се разглеждат поотделно, тъй като те се намират в причинно-следствена зависимост. В тази връзка специално внимание следва да се отделя на оценката и проектирането, като постигането на желаните крайни резултати зависи до голяма степен от обучението, взаимозаменяемостта, наличието на ефективни екипи, минимизирането на дефектите и грешките, водещи до забавяне на работните процеси. Оценяването позволява да се установи текущото състояние на организационните ресурси и протичащите процеси, а въз основа на диагностицирането - да се проектират понататъшните действия за удовлетворяване на интересите на заинтересованите страни. Постигането на всичко това предполага промяна в начина на мислене, управление и действие на работещите в организациите.

Организационното съвършенство може да се разглежда като непрекъснат стремеж към подобрение на дейностите, процесите, продуктите, услугите, както и на начините, по които организацията въздейства върху обществото (А. Ненова, 2013, с. 169). Същевременно изследователите посочват, че непрекъснатото подобрение предполага дългосрочна визия, подкрепа от страна както на ръководството, така и на целия персонал. От тази гледна точка организационното съвършенство може да се разглежда като важна част от стратегическото управление. Предпоставка за това е и фактът, че стратегическото управление, от своя страна, изисква постоянното и едновременно развитие и внедряване на стратегията, преработването и адаптирането й както към външната среда, така и към постигнатите резултати (М. Кузманова, 2008, с.172). Това предполага ориентиране на стратегическото мислене в посока на търсене на начини и средства за непрекъснати усъвършенствания и осигуряване на дългосрочен успех за организациите. Организационното съвършенство се характеризира с балансирана политика към стейкхолдърите, позволяваща увеличаване на вероятността за постигане на успехи в дългосрочен план. На практика постигането на съвършенство е изключително сложен процес, но има ключово значение за съществуването и развитието на организациите в дългосрочен аспект.

Постигането на съвършенство в организацията предполага съгласуване и ефективно управление на няколко основни компонента, за да се реализира пълно разгръщане на организационния потенциал, а именно (Х. Тужаров, 2008):

- управление на всички производствени и организационни процеси;

- постоянно усъвършенстване на тези процеси, като се съобразяват потребностите на организацията;

- усъвьршенстване на процесите чрез разработване и изпьлнение на проекти;

- гарантиране успеха на тези проекти с подходящи знания; 
- обезпечаване на всяка дейност с нужните ресурси.

Съществува разбирането, че до организационно съвършенство се достига, ако са налице някои основни компонента, сред които се извеждат следните (http://www.faqsfororgs.com):

- осъзнаване от страна на рьководството на необходимостта и съответно поддържане в организацията на разнородни екипи от хора, притежаващи различен начин на мислене, както и разнородни ценности, умения, етичност, морал;

- съсредоточаване на мисията на организацията върху резултатите и приложение на системно мислене;

- всички действия в организацията са насочени в посока на своевременно адаптиране на целите към непрекъснато променящите се условия на средата, в която тя трябва да функционира;

- организационно-управленската структура създава предпоставки за приложение на евристичен подход и формиране на екипи от различни специалисти, които да обединяват познанията и усилията си за по-висока адаптивност на организацията.

Като съвършена организация може да се характеризира онази организация, която работи в съответствие с естествените начини на развитие, мислене и действия на хора, структури, процеси и системи.

Изведени са осем принципа на съвършенство, а именно:

- подход, ориентиран към резултати;

- фокус върху потребителите;

- лидерство и постоянство на целите;

- управление чрез процеси и факти;

- подход, основаващ се на възможности за развитие и участие на хората;

- непрекъснато обучение, иновации и усъвършенстване;

- развитие на партньорства;

- социална отговорност.

Прилагането на тези принципи позволява във времето достигане до високо ниво на зрялост на организациите, в резултат на което те могат да постигнат своето съвършенство, както и да набележат стъпките за последващи промени в посока на по-нататьшното им усъвьршенстване.

Постигането на организационно съвършенство предполага ангажиране на целия персонал, на партньорите за прецизиране на изпълнението на бизнес процесите, както и работа в посока на непрекъснатото им усъвършенстване. Като фактор с водещо значение се определя качеството на управлението. Във връзка с това в специализираната литература съществува разбирането, че организационното съвършенство представлява своеобразен резултат от еволюцията на концепцията за тотално управление на качеството (К. Хаджиев, 2013, с. 306). Сама по себе си, тази концепция има стратегически характер и нейното внедряване може да се разглежда като предпоставка за постигане на съвършенство на организациите. Подобряването на качествените характеристики на процесите, продуктите, услугите е предпоставка за по-пълно удовлетворяване на интересите на стейкхолдерите и формиране на нови конкурентни предимства.

\section{2. Тотално управление на качеството}

Тоталното управление на качеството (ТУК) може да се разглежда като система, приложението на която води до постигане на ефективно развитие, поддържане и усъвършенстване на качеството в организацията, интегриране на усилията на целия персонал 
за най-пълно удовлетворяване на изискванията на потребителите, реализиране на икономии, повишаване конкурентоспособността на стопанските субекти. Водещо място сред целите на тоталното управление заема доволният клиент, който се разглежда като база за постигане на дългосрочен успех. Реализацията на това изисква формиране на работещи екипи, следящи за преодоляване на препятствията и евентуални смущения в работните процеси, както и за удовлетворяване на качествените изисквания в хода на създаването на крайните продукти и услуги. Счита се, че системите за ТУК се разглеждат като гъвкави системи, позволяващи на организацията да се адаптира непрекъснато към турбулентната среда (Г. Соседов, Б. Герасимов, Е. Герасимова, 2014, с. 189). В същото време някои изследователи посочват, че внедряването на ТУК предполага разглеждане на организацията като доставчик, а на служителя - като потребител (В. В. Ефимов, 2004, с. 134). Персоналът се възприема като интелектуалния капитал, с който фирмата разполага и чиито творчески възможности са предпоставка за развитие и усъвършенстване. ТУК се разглежда като комплексна система, ориентирана към непрекъснати подобрения в организацията (А. Литвинова, 2001, с. 90).

Концепцията ТУК е подходяща за приложение във всякакъв тип организации. Основното изискване е пълна отговорност от всички служители и работници в съответната фирма (Д. Костов, 2007, с. 142). Постигането на желаните резултати изисква съвместна работа от страна на целия персонал. Като основна цел на системата за ТУК в специализираната литература се извежда получаването на максимален ефект от дейността на организацията във всички направления. ТУК изисква използване на всички ресурси на фирмата в интерес на заинтересованите страни - потребителите, персонала, ръководството, обществото като цяло. ТУК като концепция е насочено към балансиране на взаимоотношенията с клиентите и тяхната удовлетвореност, основаващо се на отговорност на висшето ръководство и стремеж към непрекъснато усъвършенстване на организацията с активното участие на всички (М. Станимирова, 2015, с. 43). Това предполага ангажиране на на целия персонал с дейности по непрекъснато подобряване чрез многократно повторение на цикъла на Е. Деминг, включващ планиране, изпълнение, проверка и действие (PDCA). От друга страна, има изследователи, които подчертават тезата, че това повторение на цикъла PDCA позволява определяне с по-голяма точност на силните и слабите страни на организациите (А. Ненова, 2013, с. 254). В резултат на това могат да се прецизират и възможностите на стопанските субекти за удовлетворяване на потребителските предпочитания и повишаване на конкурентните преимущества. Това кореспондира с разбирането, че основно място в ТУК заема тезата, че бизнесьт трябва да се рьководи от гледна точка на очакванията на клиента (И. Николова, 2008).

Системата за ТУК изисква прилагане на процесен подход и превръщането й в неразделен компонент на управлението в организациите. Степента, в която е постигнато това, всяка организация може да определя сама, като използва определени критерии за оценка. Съпоставимостта на резултатите изисква прилагане на еднотипни методики и като такива успешно се използват учредените награди за качество. По своята същност те представляват средство за установяване на равнището на качеството в организациите и при достигане на определено ниво - получаване на съответно отличие. Оценяването с помощта на инструментариума на наградите за качество дава възможност на отделните стопански субекти да локализират усилията си в посока на повишаване на своята самооценка, т.е. самоусъвършенстване и респективно постигане на организационно съвършенство.

\section{3. Особености на наградите за качество и Европейски модел за съвършенство}

Пьрвата награда за качество, носеща едно от най-популярните имена в областта на управлението на качеството, е Награда Деминг (1951г.). С учредяването й японците изразяват своето признание към Е. Деминг за неговия принос за възстановяване на икономиката им след Втората световна война. Малко по-късно се създават Награда „Малкълм Болдридж“ в САЩ (1987 г.), Европейска награда за качество (1991 г.), Премия на 
Правителството на Руската федерация в областта на качеството (1996 г.), Германска награда за качество (The Ludwing-Erhard-Preis - 1997 г.), Японска национална награда за качество (1999 г.), Австралийска награда, Канадска награда, Награда за отлична дейност на Уест Мидльнс в Англия и др. Общото при всички награди, известни още като стимули за качество, е използването на точкова система за оценяване с максимален възможен брой точки 1000. При всяка от наградите те са разпределени в отделни групи показатели, като навсякъде приоритет се дава на удовлетвореността на клиентите. Показателите за оценка са разделени в две категории - осигуряващи и резултативни фактори. Осигуряващите фактори имат характер на възможности, които организациите могат да използват, за да формират конкурентни предимства в ключови области. Резултативните фактори се свеждат до последствията, които стопанските субекти реализират по отношение на заинтересованите страни.

Предвид гео-политическата принадлежност на България, от особено значение за местните организации е Европейската награда за качество, носеща наименованието Награда за съвършенство $\left(\mathrm{EEA}^{1}\right)$ от 2006 г. насам, разработена от $\mathrm{EFQM}^{2}$. Като основа за присъждането й се използва така наречения Модел за превъзходство (The Excellence Model). На практика, Европейската награда за съвършенство може да се разглежда като инструментариум, позволяващ оценяване на нивото на подобрения, постигнато в цялостната дейност на организацията. Основава се на цикъла PDCA, а проследяването на начина на изпълнението му в стратегически аспект дава възможност да се осъществи самооценяване на компаниите или отделни техни структурни звена. Този модел се основава на базовите постановки на ТУК, пряко кореспондиращи с принципите за съвършенство. Свеждат се до следните:

- ориентация към клиентите;

- фокус върху клиента;

- лидерство и постоянство на целите;

- управление чрез процеси и факти;

- непрекъснато обучение, иновации и подобрения;

- развитие на партньорства;

- обществена отговорност.

Тези концепции могат да бъдат прилагани успешно към всеки тип организация, независимо от размерите и сферата им на дейност. Необходимо е ръкодителите да проявяват пълна ангажираност към тях, за да се получат желаните резултати в посока на усъвършенстване на организациите.

Европейската награда за качество се присъжда на две нива - награда и призове, което позволява отличаване на повече организации с по-високи постижения. Присъжда се в четири категории: големи компании; оперативни отдели на компаниите; организации от публичния сектор; малки и средни предприятия. Организациите, постигнали високи резултати в хода на своето усъвършенстване на управлението на качеството се отличават с Европейски приз, а най-добрата организация получава Европейска награда за качество. Призът е под формата на холограмно изображение, а наградата представлява статуетка. Организацията, получила Европейската награда, има възможност да задържи при себе си статуетката в рамките на една година, което я обвързва и с ангажимента да споделя своя опит и постижения с другите, съгласно изискванията на EFQM.

При EЕА достигнатото равнище на самоусъвършенстване се определя с помощта на пет критерия за ключовите области за успех (първа група фактори), представляващи възможности за достигане на четири резултативни критерии (втора група фактори).

\footnotetext{
${ }^{1}$ EEA - European Excellence Award - Европейска награда за съвършенство

${ }^{2}$ EFQM - European Foundation for Quality Management - Европейска фондация за управление на качеството
} 
Един от основните критерии, оценяван при всички видове награди, е лидерството (критерий 1). Реализирането на мисията и визията, спазването на ценностите се намира в пряка зависимост от способността и желанието на лидерите да подпомагат тези процеси. С помощта на този критерий се оценява степента на лично участие на лидерите при осигуряване на благоприятни условия за развитие, внедряване и подобрение на управлението на качеството в организацията, постоянния контакт с клиенти, партньори и всички други обществени заинтересовани страни, както и усилията му за мотивиране на персонала. При някои награди (например „Малкълм Болдридж“) са обособени два компонента на този критерий, а именно - организационно лидерство и социална отговорност, като по този начин се търсят добри практики конкретно във всяко едно от тези направления.

Планирането в стратегически аспект (критерий 2) разглежда разработването и внедряването на стратегии и прилагане на политики, основани на предишния опит, настоящите и бъдещите очаквания на акционерите, иновиране, непрекъснато усъвършенстване в съответствие с настъпили промени и установени слабости в ключовите процеси.

Постигането на ТУК в организациите предполага наличие на персонал (критерий 3), притежаващ определени умения и способности, както и планиране на действия за повишаване на знанията му. Важен аспект, който подлежи на оценяване, са и правата, предоставяни на работещите в съответната организация, предвидените награди и отличаването на онези, които демонстрират по-добри постижения, воденето на диалог и екипната работа.

Усъвършенстването на организациите изисква и правилно управление на техните партньорства и ресурси (критерий 4). От гледна точка на ЕЕА оценяването по този критерий изисква определяне на степента на ефективно и ефикасно използване на наличните ресурси, съсредоточаване на вниманието и действията на организацията върху установяване на благоприятни партньорски взаимоотношения с доставчици и клиенти. Постигането на устойчивост в управлението на ресурсите има и екологичен аспект, тъй като способства за намаляване на негативното въздействие върху природната среда и осигурява допълнителни преимущества за организациите.

Критерий за оценка представлява и управлението на процесите (критерий 5), което би следвало да отговаря на характеристики като системност, прилагане на иновации за попълно удовлетворяване на изискванията на заинтересованите страни, увеличаване на ценностите на потребителите и акционерите, управление и развитие на контактите с клиентите.

Оценява се начинът, по който съответната организация управлява външните си партньорства и вътрешните си ресурси за постигане на своята политика и ефективност на процесите.

Втората група фактори, свързани с резултатите от дейността на организацията в областта на качеството, се свеждат до:

- постигнатото от организацията за нейните клиенти;

- постигнатото от организацията за нейния перонал;

- постигнатото от организацията за обществото като цяло;

- общото представяне по отношение на планираните приходи и ползи като цяло (ключови икономически показатели).

Първите два фактора са свързани с оценяване степента на удовлетвореност на персонала и на клиентите съответно. Степента на удовлетвореност на работещите в организацията има пряко въздействие върху тяхната мотивация, готовността им да се самоусъвършенстват, начина им на работа. Нивото на удовлетворяване на клиентите има водещо значение, както вече посочихме. Именно потребителите се определят като основен измерител на постинатото качество на продуктите и услугите, степента, в която се 
удовлетворяват потребностите, поради което тежестта на този фактор при общата оценка е най-висока. Лоялността на клиентите е от ключово значение за запазване и повишаване на пазарния дял, както и подобряване имиджа на организациите.

Когато става въпрос за обществото, на първо място трябва да се определи неговия периметър от гледна точка на конкретната организация, за да може да се оцени степента, в която тя се съобразява с неговото мнение и позиция относно дейността й. В различните сфери съществуват различни законови и нормативни изисквания, които ръководителите следва да имат предвид. Обществото на практика представляват всички заинтересовани страни (извън организацията), при което едновременното удовлетворяване на изиксванията им понякога е изключително сложен процес. Независимо от това, трябва да се намери начин за постигането му и то в стратегически план.

Общото представяне на организацията, т.е. резултатите за нея, се определя чрез оценяване с помощта на подходящи индикатори на всички бизнес начинания - финансови (приходи, разходи, печалба, растеж и др.) и нефинансови (обем произведена продукция, пазарен дял, спазване на срокове за доставка, честота на оказвани услуги, гаранционно обслужване и др.). Значението на тези резултати заема второ място в общата оценка по своята значимост.

За получаване на по-достоверна оценка, методологията на наградите за качество изисква разглеждане на най-малко три годишен период. В резултат на това може да се проследи надграждането и степента на усъвършенстване на конкретната организация. Като основни насоки, в които трябва да се работи, за да се постигне съвършенство, се определят следните няколко:

- добавяне на стойност за потребителите;

- създаване на творчество и иновации;

- ръководство с помощта на ясна визия за бъдещето;

- съобразяване с евентуалните заплахи;

- използване на таланта на хората за развитие на организациите;

- поддържане на отлични резултати, свързано с необходимостта от търсене на възможности за нови постижения в областта на качеството.

Непрекъснатото подобряване на качеството е предпоставка за постигане на организационно съвършенство. Това изисква създаване на благоприятна среда в организацията, системно проследяване на достигнатото ниво, сравняване с най-добрите, внедряване на добри практики, използване на критериите на наградите за качество за самоусъвършенстване чрез постепенно повишаване на броя точки, които организацията покрива.

\section{Заключение}

Организационното съвършенство следва да се разглежда като системен подход към управление на организацията в цялостен аспект (К. Хаджиев, 2013, с. 306). Разработеният от Европейската фондация за управление на качеството „Модел за съвършенство“ следва да се разглежда като комплекс от указания по отношение на подходите, чието прилагане ще позволи на организациите да се развиват непрекъснато в посока на усъвършенстването си. Постигането на превъзходство изисква балансиране и задоволяване на интересите на различните заинтересовани страни - както вътрешни, така и външни. Счита се, че чрез наградите за качество се благоприятства процеса на обмен на информация и споделяне на най-добрите бизнес практики и стратегии, приложението на които води до усъвършенстване на качеството в организациите като цяло. Възможността за правене на самооценка осигурява допълнителни ползи, тъй като всеки стопански субект може да определи сам достигнатото ниво, да установи своите слаби места и на тази база да предвиди конкретни действия за преодоляването им. Това следва да се разглежда като основа, върху която да се надграждат 
показателите за състоянието на организациите и в резултат на това да се „върви“ към тяхното усъвършенстване. Турбулентността на средата представлява причина организационното съвършенство да има динамичен характер, поради което се изисква възприемането му като стратегическа цел и осъществяване на действия от страна на всички работещи в съответната компания, за постигането му. В помощ на това е внедряването на ТУК и оценяване на достигнатото ниво чрез уеднаквени системи от показатели, каквито са наградите за качество. Съществуващите такива позволяват отличаване на онези компании, които са достигнали определено ниво на качество във всички аспекти от своята дейност и са се доказали през годините с поддържане на високи качествени стандарти в съответната област. Отличаването им представлява начин да се фокусира вниманието на обществото вьрху най-добрите практики, обмен на идеи и опит, с цел усъвършенстване и на други организации. Системата за ТУК включва в себе си най-доброто от световната практика при създаването на висококачествени продукти и услуги (В. Ефимов, 2000),с. 43). В резултат на това може да се подобрява имиджа на организацията и да се разширява нейното пазарно присъствие.

\section{Използвана литература / References}

1. Alkalai, Y. (2008). Evropeyski model za savarshenstvo. [Online] Available from: https://www.bcci.bg/bulgarian/bjec/news/2008/Prilozenie2.pdf [Accessed 07/09/2019]

2. Efimov, V. (2004). Uluchshenie kachestva proektov i protsessov. Uchebn. pos. Ulyyanovsk. UlGTU

3. Efimov, V. (2000).Upravlenie kachestvom: Ucheb. posobie. Ulyyanovsk: UlGTU, 141 s.

4. Hadzhiev, K. (2013). Modeli za organizatsionno savarshenstvo. Sofiya: Izd. NBU

5. Hadzhiev, K. (2010) Strategii za organizatsionna promyana v biznesa: Dinamiki na modela za organizatsionno savarshenstvo. Other. Nauchen elektronen arhiv na NBU [Online] Available from: http://eprints.nbu.bg/618/ [Accessed 18/09/2019]

6. Integrirano posobie za tsyalostno upravlenie na kachestvoto $\mathrm{v}$ sadilishtata $\mathrm{s}$ prilagane na instrumenta za organizatsionno savarshenstvo CAF JUSTICE BG 2018 [Online] Available http://www.eufunds.bg/ [Accessed 21/10/2019]

7. Kostov, D. (2007). Upravlenie na kachestvoto. Stara Zagora: Iskra M-I

8. Kuzmanova, M. (2008). Integrirana sistema za neprekasnati podobreniya v biznes organizatsiyata. Research Papers, vol.2, No5, UNSS, pp. 167-198

9. Litvinovna, A. (2001). Upravlenie kachestvom produktsii. Uchebn. pos. Volgograd: VGU, $100 \mathrm{~s}$.

10. Nenova, A. (2013). Integrirani sistemi za upravlenie na biznesa. Integriraniyat podhod kato savremenen instrument za prehod kam ,zelena“ ikonomika. Nauchen almanah na VSU Varna „Chernorizets Hrabar“, kn. 23, pp. 166-171

11. Nenova, A. (2013). Integrirani sistemi za upravlenie na kachestvoto, okolnata sreda, bezopasnostta i zdraveto $\mathrm{v}$ biznes organizatsiite. Nauchni trudove na Rusenskiya universitet. Tom 52, seriya 1.2, Ruse: RU „Angel Kanchev“, pp. 253-256

12. Nikolova, I. (2008). Teoretichna osnova na totalno upravlenie na kachestvoto - osnovni modeli i izsledvaniya. Sofiya: Softreyd

13. Sosedov, G., B. Gerasimov, E. Gerasimova. (2014). Razvitie gibkih sistem menedzhmenta kachestva gibkoy organizatsii. Voprosay sovremennoy nauki i praktiki. Universitet im. V.I. Vernadskogo. №1 (50). 2014. pp. 189-195

14. Stanimirova, M. (2015). Upravlenie na kachestvoto. Varna: Nauka i ikonomika, IU

15. Tuzharov, H. (2008). Model za uspeshen biznes EFQM. [Online] Available from: http://tuj.asenevtsi.com/EFQM/EFQM04.htm [Accessed 17/09/2019]

16. What is a perfect organization? April 25, 2016 [Online] Available from: http://www.faqsfororgs.com/what-is-a-perfect-organization [Accessed 20/10/2019]

17. http://efqm.org/success-stories 